\title{
Виталий Александрович Лихошвай: первые шаги в науке
}

\section{С.И. Бажан $\bowtie$}

Аннотация: В статье представлена информация о первых шагах научной деятельности В.А. Лихошвая, которую он начинал во Всесоюзном научно-исследовательском институте молекулярной биологии (ныне ФБУН ГНЦ ВБ «Вектор») сразу после окончания в 1976 году механико-математического факультета НГУ. Показана его трансформация из студента-математика в талантливого ученого в области математической теории биологических процессов. В популярной форме описан обобщенный химикокинетический метод моделирования сложных молекулярно-генетических систем, который стал для Виталия Александровича удачным стартом, определившим дальнейшие направления его научных исследований.

Ключевые слова: В.А. Лихошвай; моделирование молекулярно-генетических систем; обобщенный химико-кинетический метод моделирования; метод Гира; метод дробных шагов.

Для цитирования: Бажан С.И. Виталий Александрович Лихошвай: первые шаги в науке. Письма в Вавиловский журнал генетики и селекции. 2020;6(4):164-167. DOI 10.18699/Letters2020-6-20

\section{Review}

\section{Vitaly A. Likhoshvai: the first steps in science}

\section{S.I. Bazhan $\bowtie$}

Abstract: The article provides information on the first steps of V.A. Likhoshvai scientific activity, which he started at the All-Union Scientific Research Institute of Molecular Biology (now State Research Center of Virology and Biotechnology "Vector") immediately after graduating in 1976 from the Faculty of Mechanics and Mathematics of Novosibirsk State University. His transformation from a student of mathematics into a talented scientist in the field of the mathematical theory of biological processes is described. A generalized chemical-kinetic method for simulating complex molecular genetic systems is described in a popular form, which became a good start for Vitaly Likhoshvai, that determined the further directions of his scientific research.

Key words: V.A. Likhoshvai; molecular genetic systems simulation; generalized chemical-kinetic method for simulating; Gear's method; fractional steps method.

For citation: Bazhan S.I. Vitaly Likhoshvai: the first steps in science. Pisma v Vavilovskii Zhurnal Genetiki i Selektsii = Letters to Vavilov Journal of Genetics and Breeding. 2020;6(4):164-167. DOI 10.18699/Letters2020-6-20 (in Russian)

Я познакомился с Виталием Александровичем Лихошваем в июне 1976 года. Это произошло в стенах Всесоюзного научно-исследовательского института молекулярной биологии (ВНИИ МБ), ныне Государственный научный центр вирусологии и биотехнологии «Вектор». ВНИИ МБ был организован в 1974 году, в 1975 году его возглавил Лев Степанович Сандахчиев, который сформировал структуру института и лично занимался подбором кадров. Фактически ВНИИ МБ развивался как многопрофильный институт с широким набором специальностей. Отдел математического моделирования был одним из первых отделов, организованных во ВНИИ МБ. Первым руководителем отдела был Ю.Н. Ватолин. Я был принят во ВНИИ МБ и зачислен в отдел математического моделирования в ноябре 1975 года после окончания аспирантуры ИЦиГ СО АН СССР. Поскольку при подборе кадров Л.С. Сандахчиев отдавал предпочтение молодым специалистам, то очередное пополнение отдела произошло в середине 1976 года из числа студентов, выпускников физического и механико-математического факультетов НГУ, среди которых был Виталий Александрович, выпускник кафедры алгебры и математической логики.

Практически сразу у меня с Виталием Александровичем образовался прочный тандем, который сблизил нас не только по работе, но и по жизни. Наше сотрудничество очень быстро переросло в дружбу, мы дружили семьями, вместе проводили отпуска, поэтому я позволю себе здесь называть его по имени, опуская отчество.

Итак, трудовая научная деятельность Виталия началась 


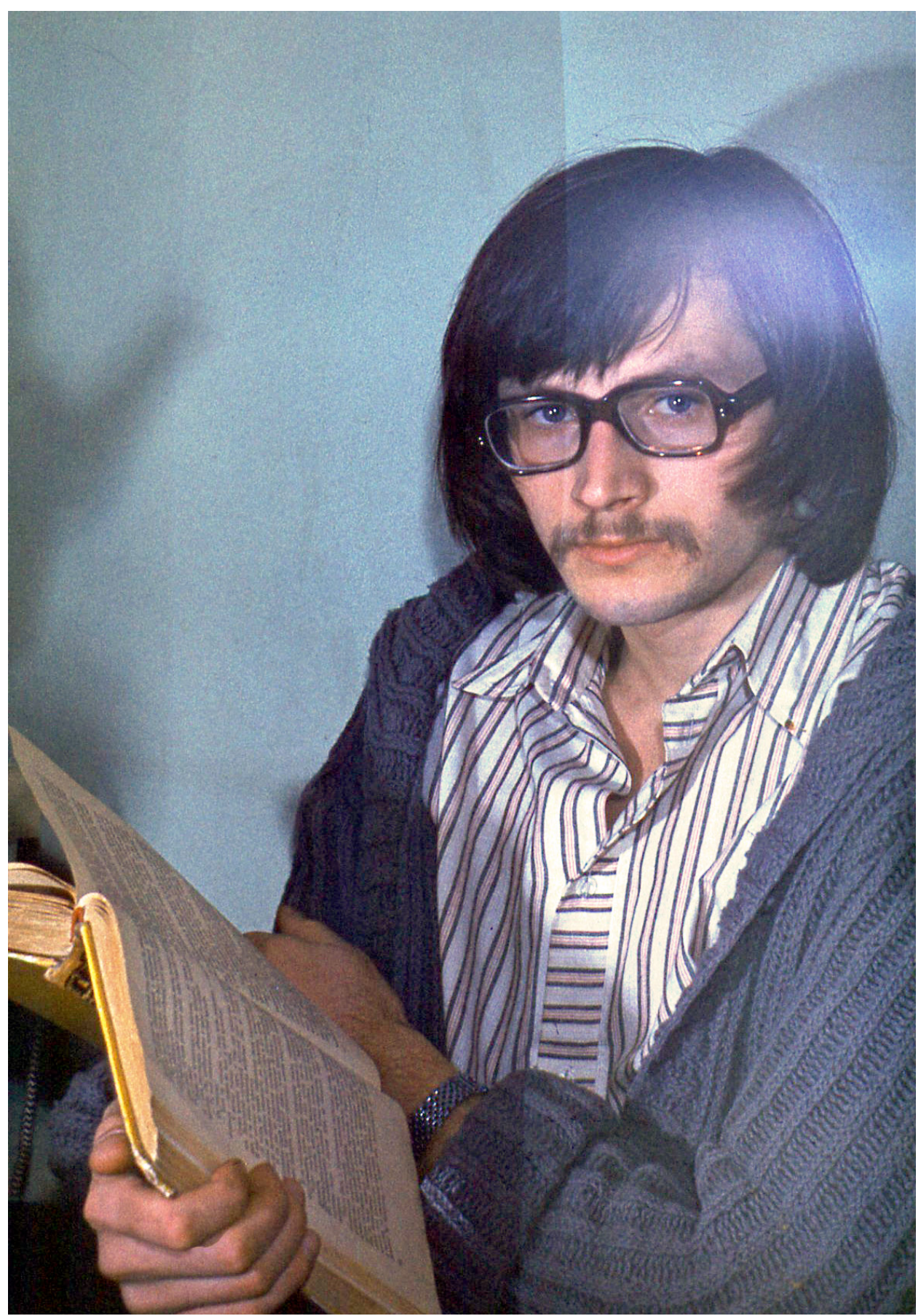

Виталий Лихошвай, 1977-1978

с его приходом во ВНИИ МБ. Для него, как, впрочем, и для всех, кто сюда устроился, всё здесь было впервые, в том числе новый коллектив, новые направления и задачи исследования. Но если мне и многим другим, кто стоял у истоков «Вектора», пришлось переквалифицироваться для работы в области вирусологии, имея за спиной биологическое, химическое или медицинское образование и опыт научной работы, то Виталию, «чистому» математику, пришлось не просто переквалифицироваться, а фактически с нуля начинать постигать азы молекулярной биологии.
Перед нами стояла задача научиться моделировать регуляцию и функционирование сложных молекулярно-генетических систем (МГС), состоящих из множества взаимосвязанных компонентов и потому требующих особых методов математического моделирования. Такие методы формализации должны были обеспечивать возможность анализа не только исходных МГС, но и моделирования динамики поведения практически любых генетических вариантов, которые можно конструировать на их основе. Иными словами, модель МГС должна разрабатываться как конструктор, со- 
стоящий из множества моделей элементарных подсистем, которые в дальнейшем могут использоваться для конструирования практически неограниченного многообразия генетических вариантов, отличающихся от исходной МГС.

После того как задача была обозначена, нужно было выбрать метод формализации и придумать алгоритм построения и расчета моделей. Здесь проявились аналитический пытливый ум и логическое мышление Виталия, которые помогли ему быстро войти в суть проблемы. Системный взгляд на проблему позволил ему целенаправленно подойти к изучению объекта исследования. Имея широкий кругозор и склонность к самообразованию, он в очень короткий срок овладел ситуацией, что приблизило нас к решению поставленной задачи.

Систематизируя и логически увязывая между собой данные о структуре, регуляции и функционировании МГС, мы пришли к выводу, что функция конструктора моделей наиболее адекватно может быть описана в терминах реакций химической кинетики, поскольку такой подход является одним из наиболее естественных, а, следовательно, и перспективных методов моделирования динамики функционирования МГС. Данный метод получил название «обобщенный химико-кинетический метод моделирования» (ОХКММ) (Likhoshvai et al., 2000).

Основу предложенного метода составляет блочный способ моделирования. Сначала исходная система представляется в виде отдельных элементов с выделением элементарных процессов, описывающих функционирование этих элементов. При этом основным свойством элементарного процесса является его локальная независимость от других процессов, то есть модель элементарного процесса в любой момент времени вполне характеризуется значениями входных переменных и собственным внутренним законом функционирования. Моделирование элементарных процессов осуществляется с помощью формальных блоков. Формальные блоки представляют собой модели химико-кинетических процессов, функционирование которые однозначно характеризуется упорядоченными списками динамических переменных и параметров и описывается системами обыкновенных дифференциальных уравнений в условиях идеального перемешивания. Модель всей системы строится из этих блоков по определенным правилам.

После того как мы определились с методом формализации, нужно было выбрать подходящий метод расчета моделей, построенных из элементарных блоков, в которых законы изменения мгновенных скоростей продуктов задаются системами обыкновенных дифференциальных уравнений. Важным свойством этих моделей было то, что для их построения применимо правило суммирования правых частей. Формально такие модели относятся к классу систем нелинейных дифференциальных уравнений. Для интегрирования таких систем мы выбрали метод Гира (Gear, 1967) и метод дробных шагов Яненко (Яненко, 1967). Второй метод интегрирования обладает замечательным свойством, которое делает его исключительно перспективным в области моделирования биосистем, построенных в терминах ОХКММ. Действительно, применение этого метода для численного решения системы дифференциальных уравнений заключается в независимом на каждом шаге интегрирования расчете каждого элементарного блока, составляющего модель. Другими словами, каждый шаг интегрирования расщепляется на такое количество подшагов, из скольких элементарных блоков состоит модель. Данное свойство мы использовали в качестве алгоритма расчета моделей, конструируемых из элементарных блоков в терминах ОХКММ. Метод дробных шагов, позволяющий рассчитывать модель путем ее расщепления по элементарным блокам, стал неотъемлемой частью компьютерной модели биосистемы.

Разработка обобщенного химико-кинетического метода моделирования была нашим коллективным творчеством (Likhoshvai et al., 2000), в котором ключевая роль в разработке компьютерной модели и программного обеспечения принадлежала Виталию.

Здесь важно отметить, что предложенная технология блочного моделирования на основе обобщенного химико-кинетического подхода позволяет алгоритмизировать процедуру построения и исследования моделей сложных молекулярно-генетических систем. Преимущество блочной технологии моделирования заключается в том, что математическая модель является открытой, то есть она может быть легко модифицирована путем добавления или удаления определенных блоков.

Модельной системой для разработки этой технологии стала молекулярно-генетическая система регуляции и функционирования бактериофага $\lambda$. Полученные результаты легли в основу кандидатской диссертации Виталия Александровича «Математическое моделирование внутриклеточного онтогенеза фага лямбда», которую он защитил в 1985 году по специальности «молекулярная биология». Здесь Виталий проявил себя высококвалифицированным специалистом как в области математики, так и в области молекулярной биологии. Я был научным руководителем его диссертационной работы, при этом Виталий был моим первым дипломированным соискателем. Результаты, полученные при моделировании внутриклеточного онтогенеза фага $\lambda$ и некоторых его мутантов, продемонстрировали универсальные свойства предложенного алгоритма, поскольку генерируемые на его основе модели хорошо описывали имеющиеся в то время экспериментальные данные.

Следует отметить, что обобщенный химико-кинетический метод моделирования обеспечивает необходимые средства для моделирования закономерностей функционирования молекулярно-генетических систем, структурнофункциональная организация которых полностью определяется структурой генома, лежащей в основе конкретной генной сети, и связями между входящими в данный геном элементами. Важно отметить, что в рамках ОХКММ структура генома описывается наиболее естественным способом - в виде генетической карты, которая представляет собой линейно упорядоченный список ориентированных генетических элементов, модели которых хранятся в базе.

Технология ОХКММ обеспечивает все основные этапы построения и анализа моделей МГС, включая:

- интеграцию и обобщение существующих знаний в рамках концептуально-логической модели;

- анализ данных и формулировку гипотез; 
- построение и верификацию модели;

- проверку гипотез и генерацию новых знаний в данной предметной области.

Действительно, динамическая модель МГС, после того как она разработана и адаптирована, становится инструментом исследования биосистемы в зависимости от внешних воздействий на любом этапе ее функционирования и с ее помощью можно ставить и решать задачи, которые затруднительно или вообще невозможно проводить в натурном эксперименте. Фактически модель в этом случае служит инструментом приобретения новых знаний о закономерностях поведения биосистемы.

Таким образом, обобщенный химико-кинетический метод моделирования был для Виталия удачным стартом, который определил дальнейшие направления его научных исследований. В наших совместных исследованиях мы применяли этот метод для моделирования индукции и антивирусного действия интерферона (Bazhan et al., 1995; Belova et al., 1995), одиночного цикла внутриклеточного размножения вируса гриппа (Бажан и др., 2009), а также для исследования механизмов репликации ВИЧ-1 (Likhoshvai et al., 2014; Ratushny et al., 2017). После перехода в 1997 году Виталия в Институт цитологии и генетики он широко использовал этот метод для моделирования генных сетей (Лихошвай и др., 2001). Докторская диссертация «Математическое моделирование и компьютерный анализ генных сетей» была посвящена дальнейшему развитию методологии моделирования молекулярно-генетических систем, включающей обобщенный химико-кинетический метод моделирования элементарных подсистем в терминах биохимических схем и обобщенных функций Хилла как оригинальный стандарт, реализующий иерархический подход к конструированию моделей генных сетей.

В данной статье я преследовал цель рассказать о первых шагах Виталия в науке в период его работы во ВНИИ МБ / ГНЦ ВБ «Вектор». Признание его как талантливого ученого в области математической теории биологических процессов произошло в период его работы в Институте цитологии и генетики СО РАН. Его научные интересы были связаны с развитием методов и теории математического моделирования молекулярно-генетических систем. Наиболее значимые результаты, полученные Виталием в этот период в различных областях математической биологии, представлены его коллегами и учениками (Т.М. Хлебодаровой, А.В. Ратушным, М.С. Савиной, Ф.В. Казанцевым, К.Д. Безматерных, Д.Н. Штокало, В.В. Мироновой, И.Р. Акбердиным и другими) в статьях, опубликованных в настоящем выпуске журнала (Ратушный, 2020; Савина и др., 2020; Хлебодарова, 2020).

\section{Список литературы / References}

Бажан С.И., Кашеварова Н.А., Хлебодарова Т.М., Лихошвай В.А Колчанов Н.А. Математическая модель внутриклеточного размножения вируса гриппа. Биофизика. 2009;54(6):1066-1080.

[Bazhan S.I., Kashevarova N.A., Khlebodarova T.M., Likhoshvai V.A.
Kolchanov N.A. A mathematical model of the intracellular reproduction of the influenza virus. Biofizika. 2009;54(6):1066-1080. (in Russian)]

Лихошвай В.А., Матушкин Ю.Г., Ратушный А.В., Ананько Е.А., Игнатьева Е.В., Подколодная О.В. Обобщенный химикокинетический метод моделирования генных сетей. Молекуляр. биология. 2001;35(6):1072-1079.

[Likhoshvai V.A., Matushkin lu.G., Ratushnyi A.V., Ananko E.A., Ignatieva E.V., Podkolodnaya O.V. Generalized chemical-kinetic method for modeling gene networks. Molekulyarnaya Biologiya = Mol. Biol. 2001a;35(6):1072-1079. (in Russian)]

Ратушный А.В. В память о Виталии Александровиче Лихошвае, научном наставнике и учителе. Письма в Вавиловский журнал генетики и селекции. 2020.6(4):179-184. DOI 10.18699/Letters2020-6-22.

[Ratushny A.V. In memory of Vitaly A. Likhoshvai, scientific mentor and teacher. Pisma $v$ Vavilovskii Zhurnal Genetiki i Selektsii $=$ Letters to Vavilov Journal of Genetics and Breeding. 2020;6(4):179-184. DOI 10.18699/Letters2020-6-22. (in Russian)]

Савина М.С., Казанцев Ф.В., Безматерных К.Д., Штокало Д.Н., Миронова В.В., Акбердин И.Р. Памяти Виталия Александровича Лихошвая: уроки, беседы и воспоминания. Письма в Вавиловский журнал генетики и селекции. 2020;6(4):193-198. DOI 10.18699/Letters2020-6-25.

[Savina M.S., Kazantsev F.V., Bezmaternykh K.D., Shtokalo D.N., Miro-nova V.V., Akberdin I.R. In memory of Vitaly A. Likhoshvai: lessons, conversations and memories. Pisma v Vavilovskii Zhurnal Genetiki i Selektsii = Letters to Vavilov Journal of Genetics and Breeding. 2020;6(4):193-198. DOI 10.18699/Letters2020-6-25. (in Russian)]

Хлебодарова Т.М. О решенных и нерешенных проблемах биологии в исследованиях В.А. Лихошвая. Письма в Вавиловский журнал генетики и селекции. 2020;6(4):168-178. DOI 10.18699/Letters2020-6-21. [Khlebodarova T.M. On solved and unresolved biology problems in research of V.A. Likhoshvai. Pisma $v$ Vavilovskii Zhurnal Genetiki i Selektsii = Letters to Vavilov Journal of Genetics and Breeding. 2020;6(4):168-178. DOI 10.18699/Letters2020-6-21. (in Russian)]

Яненко Н.Н. Метод дробных шагов решения многомерных задач математической физики. Новосибирск: Наука. Сибирское отделение, 1967;196 с.

[Yanenko N.N. The method of fractional steps for solution of multidimensional problems of mathematical physics. Novosibirsk: Science. Siberian branch, 1967;196 p. (in Russian)]

Bazhan S.I., Likhoshvay V.A., Belova O.E. Theoretical analysis of the regulation of interferon expression during priming and blocking. J. Theoretical Biol. 1995;175:149-160.

Belova O.E., Likhoshvai V.A., Bazhan S.I., Kulichkov V.A. Computer system for investigation and integrated description of molecular-genetic system regulation of interferon induction and action. Comput. Appl. Biosci. 1995;11(2):213-218.

Likhoshvai V.A., Khlebodarova T.M., Bazhan S.I., Gainova I.A. Chereshnev V.A., Bocharov G.A. Mathematical model of the Tat-Rev regulation of HIV-1 replication in an activated cell predicts the existence of oscillatory dynamics in the synthesis of viral components. BMC Genomics. 2014;15(12):S1. DOI 10.1186/1471-2164-15-S12-S1.

Likhoshvai V.A., Matushkin Yu.G., Vatolin Yu.N., Bazhan S.I. A Generalized chemical kinetic method for simulating complex biological systems. A computer model of $\lambda$ phage ontogenesis. Comput. Technolog. 2000;5:87-99.

Gear C.W. The numerical integration of ordinary differential equations. Math. Comp. 1967;146-156.

Ratushny A.V., De Leenheer P., Bazhan S.I., Bocharov G.A., Khlebodarova T.M., Likhoshvai V.A. On the Potential for Multiscale Oscillatory Behavior in HIV (Chapter 34). In Global Virology II - HIV and NeuroAIDS / P. Shapshak, AJ. Levine, B.T. Foley, C. Somboonwit, E. Singer, F. Chiappelli, J.T. Sinnott (Eds.). New York, NY 10013, USA: Springer Science+Business Media LLC 2017;897-924. DOI 10.1007/978-14939-7290-6. 